\title{
Air Quality and Health Cobenefits of Different Deep Decarbonization Pathways in California
}

\author{
Bin Zhao ${ }^{*}{ }^{\dagger}, \#$, Tianyang Wang ${ }^{\ddagger, \S, \#, ~ Z h e ~ J i a n g ~}{ }^{\dagger}$, Yu Gu$^{\dagger}$, Kuo-Nan Liou ${ }^{\dagger}$, Nesamani \\ Kalandiyur ${ }^{\S}$, Yang Gao", Yifang Zhu ${ }^{*}, \neq, \nabla$ \\ †Joint Institute for Regional Earth System Science and Engineering and Department of \\ Atmospheric and Oceanic Sciences, University of California, Los Angeles, California 90095, \\ United States \\ \#Institute of Environment and Sustainability, University of California, Los Angeles, California \\ 90095, United States

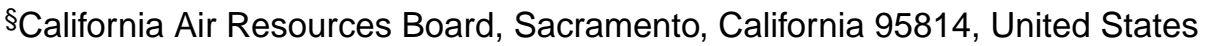 \\ "Key Laboratory of Marine Environmental Science and Ecology, Ministry of Education/Institute for \\ Advanced Ocean Study, Ocean University of China, Qingdao 266100, P. R. China \\ ${ }^{\nabla}$ Environmental Health Sciences Department of UCLA Fielding School of Public Health, \\ University of California, Los Angeles, California 90095, United States
}

\section{Abstract}

As the world's fifth-largest economy, California has committed to reduce its greenhouse gas (GHG) emissions by $80 \%$ below 1990 levels by 2050 . While previous studies have shown that GHG reductions could synergistically decrease air pollutant emissions and protect public health, limited research has been conducted to compare the health cobenefits of different technology pathways toward deep decarbonization. Using an integrated approach that combines energy and emission technology modeling, high-resolution chemical transport simulation, and health impact assessment, we find that achievement of the $80 \%$ GHG reduction target would bring substantial air quality and health cobenefits. The cobenefits, however, highly depend on the selected technology pathway largely because of California's relatively clean energy structure. Compared with the business-as-usual levels, a decarbonization pathway that focuses on electrification and clean renewable energy is estimated to reduce concentrations of fine particulate matter $\left(\mathrm{PM}_{2.5}\right)$ by 18 $37 \%$ in major metropolitan areas of California and subsequently avoid about 12100 (9600-14 600) premature deaths. In contrast, only a quarter of such health cobenefits, i.e., 2800 (2300-3400) avoided deaths, can be achieved through a pathway focusing more on combustible renewable fuels. After subtracting the cost, the net monetized benefit of the electrification-focused pathway still

\footnotetext{
*Corresponding Authors: Phone: +1-3108254324; yifang@ucla.edu (Y.Z.). Phone: +1-3109231612; zhaob1206@ucla.edu (B.Z.). \#B.Z. and T.W. contributed equally to this work.

Supporting Information

The Supporting Information is available free of charge on the ACS Publications website at DOI: 10.1021/acs.est.9b02385.

Additional information about the development of future scenarios, configuration of chemical transport and health assessment model, and evaluation of meteorological and chemical simulations; Figures S1 and S2; Table S1-S4 (PDF)

The authors declare no competing financial interest.
} 
exceeds that of the renewable fuel-focused pathway, indicating that a cleaner but more expensive decarbonization pathway may be more preferable in California.

\section{Graphical Abstract}

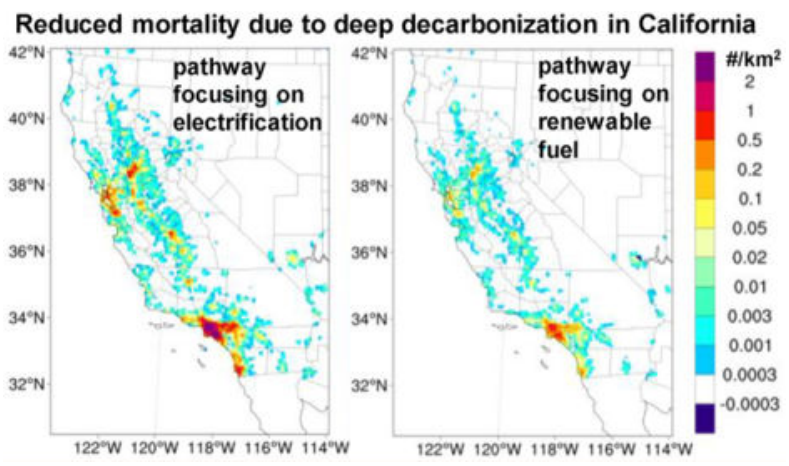

\section{INTRODUCTION}

California, the most populous state in the United States and the world's fifth-largest economic entity, has made an aggressive commitment to reduce its greenhouse gas (GHG) emissions by $80 \%$ from the 1990 levels by the year 2050 (Executive Order S-3-05). ${ }^{1}$ Since major sources of GHGs are usually also major sources of air pollutants, policy designed to reduce GHGs could synergistically reduce the coemitted pollutants, leading to potential cobenefits for public health. ${ }^{2-4}$ Such cobenefits are important for California since it is home to 7 of the top 10 U.S. cities with the highest concentrations of fine particulate matter $\left(\mathrm{PM}_{2.5}\right){ }^{5}$ Deep decarbonization policy could be an effective way to simultaneously meet the ambitious GHG emission reduction targets and improve ambient air quality in California.

Numerous studies have evaluated the effects of decarbonization policies on air quality and public health over global, continental, and regional scales, including California. ${ }^{2-4,6-9}$ Almost all of them found that GHG emission controls result in air quality improvement and health cobenefits, which could offset a fraction of or even exceed the mitigation costs, depending on geographical region and policy stringency. For California, Zapata et al. ${ }^{6}$ developed a scenario which meets the official $80 \%$ GHG reduction target at the lowest cost, and estimated that annual air pollution-associated premature deaths in 2050 would drop by 24-26\% relative to business-as-usual (BAU) levels.

Decarbonization could be achieved via various technology pathways or policy options.

Different technology pathways are associated with different air pollutant emissions and thus may lead to distinct health cobenefits. ${ }^{3,7,10,11}$ Thompson et al. ${ }^{3}$ compared the air quality and health cobenefits of climate policies targeting all economic sectors and those targeting individual sector (power plants or transportation) in the United States. They found that, for the same GHG reduction, economy-wide policies have larger net health cobenefits than single-sector policies. Shindell et al. ${ }^{10}$ compared the GHG and air pollutant reduction efficiencies of $\sim 400$ emission control measures, and identified 14 that could simultaneously reduce projected warming $\sim 0.5^{\circ} \mathrm{C}$ by 2050 and improve human health globally. Compared 
with global or U.S. studies above, the impact of choice of decarbonization technology on health cobenefits is expected to be greater in California, because California has a relatively clean energy structure dominated by natural gas and petroleum products. ${ }^{12}$ It is wellestablished that cutting down GHG emissions from coal-using facilities significantly reduces coemitted pollutants. ${ }^{13,14}$ For natural gas-using sources, however, cobenefits can be achieved only through certain decarbonization technologies because of a lower emission rate per unit energy at present. ${ }^{15}$ Very few studies have evaluated the air quality and health cobenefits of different decarbonization pathways in California. ${ }^{8}$ Kleeman et al. ${ }^{8}$ examined various GHG reduction pathways for the state's transportation sector. However, California's ambitious $80 \%$ GHG reduction target requires adoption of decarbonization measures across all economic sectors. ${ }^{6}$ A systematic evaluation and comparison of different pathways to realize the state's aggressive decarbonization target and their health cobenefits has not been conducted previously.

In this study, we aim to investigate how much the health cobenefits will change with different technology pathways for deep decarbonization in California, and whether the cobenefit difference is large enough to justify the implementation of a cleaner but more expensive technology pathway. In accordance with this objective, we design two extreme decarbonization pathways using a sophisticated energy and emission technology model. Both pathways exactly meet the overall $80 \%$ GHG reduction target, but one aims to reduce cost and the other aims to improve air quality and public health. We subsequently conduct high-resolution chemical transport simulation using the Weather Research and Forecasting Model with Chemistry (WRF-Chem) to estimate the air quality cobenefits and employ the Environmental Benefit Mapping and Analysis Program (BenMAP-CE) to assess the monetized health cobenefits of the two extreme decarbonization pathways.

\section{METHODOLOGY}

\section{Development of Decarbonization Scenarios.}

In this study, we develop an energy and emission technology model to project GHG and air pollutant emissions from 2010 to 2050, based on a multisector simulation of California's population, economy, energy structure and technologies, and emission characteristics and control technologies. The 2010 baseline combustion-related GHG emissions are calculated based on sector-specific energy demands from the U.S. Energy Information Administration (EIA) ${ }^{12}$ and energy carbon density from the literature. ${ }^{16-18}$ Noncombustion GHG emissions (except land-based emissions) in 2010 are obtained from the California Air Resources Board (CARB). ${ }^{16}$ Land-based GHG emissions (forest, wetlands, etc.) are not included, though they have now been inventoried for California. ${ }^{19}$

We develop three scenarios for the year 2050: BAU and two extreme deep decarbonization scenarios (DD1 and DD2). The BAU scenario reflects population and economic growth assumptions with no additional climate policy impacts after 2010 (see details in Supporting Information, SI). The DD1 and DD2 scenarios will achieve the same target of 80\% GHG emission reduction below the 1990 level, but are driven by distinct policy goals: DD1 is a cobenefit driven pathway aiming to improve air quality and human health; DD2 is a more conventional cost-driven pathway, aiming to reduce GHG abatement cost. On the basis of 
these clearly defined policy goals, we give priority to cleaner technologies (mainly electrification and clean renewable energy) in DD1 and cheaper ones (mainly combustible renewable fuels) in DD2. We acknowledge that the optimal technology pathway can be anywhere between the two extreme scenarios; however, this study is not intended to cover all decarbonization pathways, but serves as a first step to investigate the impacts of different GHG abatement policies on health cobenefits. The key decarbonization strategies in BAU, DD1, and DD2 scenarios are summarized in Table 1. For example, the electrification rates in the DD1 scenario are 10-15\% higher than those in the DD2 scenario for sectors of agriculture, industry, commercial, residential, and oil production and refinery. Moreover, the DD1 scenario has much larger penetrations of electric vehicles in the transportation sector, wind and solar power in electricity generation sector, and roof-top solar power in industry, commercial, and residential sectors. In contrast, the DD2 scenario is characterized by larger shares of renewable fuels for combustion sources in the sectors of industry, commercial, residential, transportation, and electricity generation. The lifecycle GHG emission factors of various types of renewable fuels are obtained from previous study ${ }^{18}$ and are not considered as zero.

While the two scenarios are different, they are both subject to four groups of constraints, i.e., GHG reduction target, technology and resource availability, policy plausibility and current policy trend, and cross-sectorial consistency (see details in the SI). Due to these constraints, DD1 and DD2 share many common technologies and assumptions, including a 80\% renewable portfolio standard (RPS) in retail electricity generation ${ }^{20}$ electrification in almost all end-use sectors, cogeneration in industry, commercial, and residential sectors, and application of renewable fuels (bioethanol, biodiesel, biomass pellets, and renewable gases) in most end-use sectors. These strategies are necessary in both scenarios to realize the aggressive $80 \%$ reduction target and to comply with the existing California legislations..$^{20-23}$ Besides, we apply the same smart growth and technology improvement assumptions to both scenarios, including building energy efficiency increase, ${ }^{23}$ smart growth in urban areas to reduce passenger vehicle mileage traveled (VMT), ${ }^{21,22}$ vehicle fuel efficiency increase, and industrial energy efficiency increase (see details in the SI). For noncombustion GHG emissions in 2050, the BAU scenario assumes similar per capita levels as in 2010, while the DD1 and DD2 scenarios both assume similar reductions as previous study, ${ }^{24}$ i.e., by $65 \%$.

We project the 2050 emissions of $\mathrm{PM}_{2.5}$, nitrogen oxides $\left(\mathrm{NO}_{X}\right)$, reactive organic gas (ROG), ammonia $\left(\mathrm{NH}_{3}\right)$, sulfur dioxide $\left(\mathrm{SO}_{2}\right)$, and carbon monoxide $(\mathrm{CO})$ by sector based on the 2010 data from CARB's California Emissions Projection Analysis Model (CEPAM) database. ${ }^{25}$ In each of the three 2050 scenarios, the emissions are calculated using projected growth rates, technology mix, and emission factors of individual technologies. For new technologies with high pretreatment emissions (such as biomass pellet combustion), we adjust their emission factors to comply with the New Source Performance Standards (NSPS). ${ }^{26}$ Finally, we convert the county-level and source-specific emissions into $4 \times 4 \mathrm{~km}^{2}$ gridded data based on high-resolution spatial distribution information provided by the California Nexus (CalNex) project. ${ }^{27}$ 


\section{Chemical Transport Modeling.}

We simulate the impact of deep decarbonization on air quality using WRF-Chem version 3.9.1, a fully coupled meteorology-chemistry model. For both 2010 and 2050, the simulations are conducted in January, April, July, and October, which represent winter, spring, summer, and fall, following a number of previous studies. ${ }^{28-30} \mathrm{We}$ apply the model to two nested domains: Domain 1 covers the western United States and its surrounding areas at a $12 \times 12 \mathrm{~km}^{2}$ horizontal resolution; Domain 2 covers California with a $4 \times 4 \mathrm{~km}^{2}$ resolution (Figure 1). The vertical resolution of the WRF-Chem includes 24 layers from the surface to $100 \mathrm{hPa}$, with denser layers at lower altitudes to resolve the planetary boundary layer (PBL). We employ an extended Carbon Bond 2005 (CB05) ${ }^{31}$ with chlorine chemistry $^{32}$ coupled with the Modal for Aerosol Dynamics in Europe/Volatility Basis Set (MADE/VBS). ${ }^{28,33}$ MADE/VBS uses a modal aerosol size representation and an advanced secondary organic aerosol (SOA) module based on the VBS approach. The aqueous-phase chemistry is based on the AQChem module used in the Community Multiscale Air Quality (CMAQ) model. ${ }^{28}$ The physical options and initial and boundary conditions are described in the SI.

The anthropogenic emissions in Domain 1 are derived from the National Emission Inventory $(\mathrm{NEI})^{34}$ in 2011, which is the closest year available. We scale the NEI 2011 inventory to the 2010 levels according to the "NEI trend report". ${ }^{35}$ The anthropogenic emission estimates from 2010, and the three 2050 scenarios obtained in this study are used as input for Domain 2. The biogenic, wind-blown dust, sea-salt, and wildfire emissions are calculated online in WRF-Chem (see details in the SI). We compare simulated meteorological parameters and concentrations of $\mathrm{O}_{3}, \mathrm{PM}_{2.5}$, and its chemical components with surface observational data, and find a generally good model-measurement agreement (see details in the SI).

\section{Health Impact Assessment.}

We quantify $\mathrm{PM}_{2.5}$ - and $\mathrm{O}_{3}$-associated mortalities, which contribute the most to the monetized health impacts of air pollution in the U.S.A., ${ }^{36,37}$ using the BenMAP-CE model version 1.3.7. ${ }^{38}$ The model calculates changes in long-term health outcomes based on ambient air pollutant concentration changes, using concentration response functions (CRFs). We apply CRFs reported by Turner et al., ${ }^{39}$ which are derived from a large prospective study - the American Cancer Society Cancer Prevention Study II. The CRFs associate all-cause premature mortality with annual average $\mathrm{PM}_{2.5}$ concentrations and maximum daily 8-h average $\mathrm{O}_{3}$ concentrations (MDA8). They are updated versions of Krewski et al..$^{40}$ and Jerrett et al., ${ }^{41}$ which have been widely used for assessment of $\mathrm{PM}_{2.5}$ - and $\mathrm{O}_{3}$-associated mortality burdens, respectively, especially in the U.S.A. ${ }^{39,42}$ Grid level demographic data and baseline mortality rates are obtained from the default database in BenMAP, which is elaborated in the SI. The 95\% confidence intervals (CI) are calculated using Monte Carlo analysis based on the uncertainty in the parameters of CRFs. We apply the "value of statistical life (VSL)" approach ${ }^{43}$ to monetize the mortality burdens. The unit value of VSL is assumed to be 9.0 million U.S. dollars (with the 2017 inflation rate). This is an intermediate value of many studies and is consistent with U.S. EPA's Regulatory Impact Analyses (RIAs). ${ }^{38}$ 


\section{Cost Analysis.}

We conduct a bottom-up estimate of the GHG abatement cost of the two decarbonization scenarios by multiplying the unit cost of individual technologies/strategies and total GHG reductions attributed to the corresponding strategy. The unit abatement cost for different technologies and strategies (unit: $2017 \$$ / ton of $\mathrm{CO}_{2} \mathrm{e}$ ) are summarized in Table $\mathrm{S} 3$ based on best available data from various studies. ${ }^{44-47}$ For strategies with no suitable cost data, we assume that the abatement cost equals to the carbon price of the Cap-and-Trade program in California. ${ }^{48}$ We realized the uncertainty of the cost analysis, and therefore only focused on the relative cost-effectiveness of the two scenarios instead of the absolute value of cost estimate.

\section{RESULTS}

\section{Emission Changes Due to Decarbonization Policies.}

Figure 2 shows the historical and projected GHG emissions in California. In the BAU scenario, the GHG emissions are projected to increase slightly by $6 \%$ in 2050 from the 2010 levels, mainly as a result of increased energy consumption due to a growing population and economy. In either DD1 or DD2, the $2050 \mathrm{GHG}$ emissions are $82 \%$ lower than the BAU levels, or 80\% lower than the 1990 levels, meeting the requirement of the Executive Order S-3-05. The fractional contributions of individual sectors to GHG reductions from BAU to DD1 or DD2 are very similar, since aggressive decarbonization technologies are deployed in all major sectors in both DD1 and DD2. For both scenarios, transportation is the largest contributor to GHG reductions (with fractional contributions of $42-46 \%$ ), followed by electricity generation (23-24\%). The other sectors each contribute $2-12 \%$ of the total reductions.

Figure 3 summarizes the statewide emissions of $\mathrm{PM}_{2.5}, \mathrm{SO}_{2}, \mathrm{NH}_{3}, \mathrm{NO}_{X}$, and ROG in 2010 and under different scenarios in 2050. From 2010 to 2050, in the BAU scenario, $\mathrm{NO}_{X}$ emissions decrease by nearly $50 \%$ and the emission changes of other pollutants are within $15 \%$. The emission changes result from a combination of energy consumption growth and existing environmental policies (see details in the SI).

The implementation of deep decarbonization strategies in the DD1 scenario reduces 2050 emissions of $\mathrm{PM}_{2.5}, \mathrm{SO}_{2}, \mathrm{NH}_{3}, \mathrm{NO}_{X}$, and $\mathrm{ROG}$ by $33 \%, 37 \%, 34 \%, 34 \%$, and $18 \%$, respectively, from the BAU levels. The emissions from nearly all source types (point source, area source, and transportation source) are reduced noticeably. The main reasons for the reductions include lower energy consumption due to energy efficiency improvement and deployment of cogeneration technology, as well as a shift toward cleaner energy sources through electrification in end-use sectors (including promotion of electric vehicles) and application of clean renewable energy in electricity generation (detailed in Table 1). $\mathrm{NH}_{3}$ is a special case. Its emission reduction is largely induced by improved livestock management with the objective to reduce $\mathrm{CH}_{4}$, a GHG with larger global warming potential (GWP) than $\mathrm{CO}_{2} \cdot{ }^{24}$ It should be noted that the percentage of reduction of air pollutant emissions from BAU to DD1 (18-37\%) are considerably smaller than those of GHG (82\%). This is because a large fraction of air pollutants originates from sources that are not directly related to 
energy use, such as industrial processes, fugitive dust, solvent use, agricultural residue burning, fertilizer application, and so forth. These sources account for a small fraction of or even no GHG emissions, therefore they are not or only moderately controlled by the decarbonization strategies.

The emissions of all pollutants in the DD2 scenario are between BAU and DD1. The emissions of $\mathrm{PM}_{2.5}, \mathrm{SO}_{2}, \mathrm{NH}_{3}, \mathrm{NO}_{X}$, and ROG are $6 \%, 10 \%, 24 \%, 10 \%$, and $14 \%$ lower than those of the BAU scenario, respectively. Compared with DD1, a larger share of the final energy demand in DD2 is supplied by direct combustion of renewable fuels rather than electricity. In addition, less electricity in DD2 is generated from clean renewable energy such as wind and solar. The different decarbonization strategies explain the higher air pollutant emissions in DD2 than DD1, since combustion of renewable fuels in end-use sectors generally produces more air pollutants than electricity generation from wind and solar. The emission difference between DD1 and DD2 is more pronounced for $\mathrm{PM}_{2.5}, \mathrm{SO}_{2}$, and $\mathrm{NO}_{X}(>27 \%)$, as compared to $\mathrm{NH}_{3}$ and $\mathrm{ROG}(\triangle 4 \%)$, because a large portion of the former three pollutants is emitted by combustion sources.

\section{Air Quality Cobenefit of Decarbonization Policies.}

Figure 4a,b shows the fractional reductions in annual mean concentrations of $\mathrm{PM}_{2.5}$ and $\mathrm{O}_{3}$ (measured in MDA8) from the BAU to DD1/DD2 scenarios, representing the air quality cobenefits of deep decarbonization policies. Figure $4 \mathrm{c}-\mathrm{f}$ further illustrate the spatial distribution of the concentration reductions. Implementation of deep decarbonization policies in the DD1 scenario lowers the spatially averaged annual $\mathrm{PM}_{2.5}$ concentration in California by $0.87 \mu \mathrm{g} / \mathrm{m}^{3}(16.6 \%)$. In contrast, the reduction in DD2 is only $0.21 \mu \mathrm{g} / \mathrm{m}^{3}$ $(4.1 \%)$, about a quarter of DD1. The spatial distribution of $\mathrm{PM}_{2.5}$ reductions is not even (Figure 4c,d). Over four largest metropolitan regions (Los Angeles County, San Francisco Bay Area, Sacramento County, and San Diego County, see Figure 1 for their spatial ranges), the $\mathrm{PM}_{2.5}$ reductions (18-37\% in DD1 and 5-9\% in DD2) are considerably larger than the whole state (Figure 4a,c,d). In particular, in the Los Angeles County-the most populous county in the United States- $\mathrm{PM}_{2.5}$ concentrations are reduced by about $33 \%$ and $7 \%$, in the DD1 and DD2 scenarios, respectively. The absolute reductions over urban Los Angeles are $>8 \mu \mathrm{g} / \mathrm{m}^{3}$ in DD1 and $>1.5 \mu \mathrm{g} / \mathrm{m}^{3}$ in DD2 (Figure $4 \mathrm{c}, \mathrm{d}$ ). The greater reduction in metropolitan areas is explained by the fact that a larger share of air pollutants in urban areas comes from combustion sources which are more sensitive to decarbonization policies than noncombustion sources. Figure S2 further illustrates the reductions in different chemical components of $\mathrm{PM}_{2.5}$ from BAU to DD1/DD2. All major components, including sulfate, nitrate, ammonium, black carbon (BC), organic aerosol (OA), and "other components", contribute to the $\mathrm{PM}_{2.5}$ reductions, with the largest contributions from OA and "other components".

The reduction in $\mathrm{PM}_{2.5}$ concentrations will likely help California to meet the National Ambient Air Quality Standard (NAAQS). Under the BAU scenario, about 22.7 million people in California are exposed to $\mathrm{PM}_{2.5}$ concentrations that exceed the NAAQS (12 $\mu \mathrm{g} / \mathrm{m}^{3}$ for annual $\mathrm{PM}_{2.5}$ concentration), accounting for $46 \%$ of the state's total population in 2050. This number drops dramatically to 7.4 million in the DD1 scenario, 67\% lower than the 
BAU level. In the DD2 scenario, however, the number is 20.0 million, only $12 \%$ lower than BAU. This results indicate that, compared to $\mathrm{PM}_{2.5}$ concentration, the population living in nonattainment areas is more sensitive to technology pathway, as the decarbonization policies favor $\mathrm{PM}_{2.5}$ reduction over more polluted regions.

For $\mathrm{O}_{3}$, the spatially averaged concentrations in California are reduced slightly from BAU by about $0.58 \mathrm{ppb}(1.5 \%)$ and $0.25 \mathrm{ppb}(0.6 \%)$ in DD1 and DD2, respectively (Figure 4b). The small sensitivity of $\mathrm{O}_{3}$ to emission reductions is because, on the one hand $>70 \%$ of the ambient $\mathrm{O}_{3}$ concentration is background $\mathrm{O}_{3},{ }^{49-53}$ and on the other hand small $\mathrm{NO}_{X}$ emission reduction usually has little or even negative effects on $\mathrm{O}_{3}$ concentration. ${ }^{54-56}$ In both DD1 and DD2, the $\mathrm{O}_{3}$ concentrations are reduced in the majority of the state because of a prevalent $\mathrm{NO}_{X}$-limited regime (Figure 4e,f). However, $\mathrm{O}_{3}$ concentrations are elevated in the populous urban centers of Los Angeles and the San Francisco Bay Area due to a volatile organic compound (VOC)-limited regime, leading to an increase in premature mortality (see Figure 5e,f, and associated discussion below). $\mathrm{O}_{3}$ concentrations reduce by $\sim 1.5 \%$ in DD1 and $\sim 0.7 \%$ in DD2 in the Sacramento County and the San Diego County, similar to the statewide reduction ratios.

\section{Health Cobenefit of Decarbonization Policies.}

The changes in $\mathrm{PM}_{2.5}$ and $\mathrm{O}_{3}$ concentrations lead to changes in health outcomes, as illustrated in Figure 5. The $\mathrm{PM}_{2.5}$ reduction due to deep decarbonization policies in the DD1 scenario is estimated to avoid about 12200 (95\% confidence interval, 9700-14 600) premature deaths annually from the BAU levels. In contrast, the avoided $\mathrm{PM}_{2.5}$-related premature deaths in the DD2 scenario are 2700 (2200-3300), accounting for about a quarter of those in DD1 (Figure 5a). The majority of avoided mortality occurs over urban areas because of population density (Figure $5 \mathrm{c}, \mathrm{f}$ ). The four largest metropolitan regions contribute about $60 \%$ of the total avoided premature deaths in California, and the Los Angeles County alone contributes about $40 \%$. Given the large population densities in urban areas, the inhomogeneous $\mathrm{PM}_{2.5}$ concentration reductions with peaks in metropolitan regions (Figure $4 \mathrm{c}, \mathrm{d})$ lead to an enhanced reduction in $\mathrm{PM}_{2.5}$-related premature mortality that is disproportionate to reduction in state-average $\mathrm{PM}_{2.5}$ concentration.

In contrast to $\mathrm{PM}_{2.5}$, the mortality changes due to $\mathrm{O}_{3}$ are much smaller. The decarbonization policies in DD1 and DD2 are estimated to increase 60 (20-110) premature deaths and avoid 120 (30-210) premature deaths annually in California, respectively (Figure 5b). These changes result from a combination of the mortality increase in urban centers of Los Angeles and the San Francisco Bay Area, and the reduction in the rest of the state (Figures 5e,f). In the DD1 scenario, the former factor (i.e., increase in urban centers) dominates over the latter due to a large urban population density, leading to an overall slight increase in $\mathrm{O}_{3}$-related mortality. When the $\mathrm{PM}_{2.5^{-}}$and $\mathrm{O}_{3}$-related mortalities are taken together, 12100 (9600-14 600 ) and 2800 (2300-3400) premature deaths are estimated to be avoided annually compared with the BAU levels as a result of decarbonization strategies envisaged in the DD1 and DD2 scenarios, respectively. The corresponding monetized health cobenefits are estimated to be about 109 (87-131) and 25 (20-30) billion of 2017 U.S. dollars. 


\section{DISCUSSION}

Our results indicate that achievement of California's $80 \%$ GHG reduction target could have substantial air quality and health cobenefits. The air quality improvement is especially pronounced in severely polluted urban areas, thus contributing to the State Implementation Plans to comply with the NAAQS. The improved air quality is estimated to avoid 12100 (9600-14 600) premature deaths annually, equivalent to about 2.5 avoided deaths per 10000 residents each year. Therefore, a full achievement of California's GHG target is highly recommended for the sake of protecting public health. In addition to the statewide target, California aims to prioritize GHG reduction investments to disadvantaged and low-income communities, as required by Senate Bill 535. ${ }^{57}$ Future studies are needed to refine the spatial allocation of GHG reductions to maximize the air quality and health cobenefits in disadvantaged communities.

A unique and important finding of this study is that the health cobenefits depend strongly on the technological pathway toward deep decarbonization. Previous studies have shown that, for a small GHG reduction goal $(<20 \%)$, strategies that target different economic sectors could lead to remarkably different health cobenefits. ${ }^{3,7}$ In contrast to sector-specific strategies for low GHG reduction targets, California's ambitious $80 \%$ reduction goal requires stringent GHG control measures across all major economic sectors. Many decarbonization technologies such as electrification, biofuel, and grid electricity denitrification are needed in all plausible pathways to achieve the target, hence the degree of freedom to design the pathway is small (see Methodology Section). Whether the health cobenefit still depends on the choice of technology pathway is unclear. In this study, we show that a technology pathway focusing on electrification and clean renewable energy (DD1) results in four times more health cobenefits than a pathway featuring combustible renewable fuel application (DD2). With the former pathway, two-thirds less population in 2050 will be living in nonattainment areas of the $\mathrm{PM}_{2.5}$ NAAQS than the latter one. An advantage of combustible renewable fuels, however, is that they impose smaller impact on the current energy supply and consumption systems and hence are less costly. To better compare the cost-effectiveness of the two pathways, we conduct a bottom-up cost analysis, and the results are summarized in Table S4. While the direct GHG abatement cost of the electrification-focused pathway is about $\$ 25$ billion larger than the renewable fuel-focused pathway, the net benefit (i.e., health cobenefit minus abatement cost) of the electrificationfocused pathway is $\$ 59$ billion greater. Therefore, a cleaner but more expensive decarbonization pathway may be more preferable in California. The results indicate that the health cobenefits, which have not been considered in most climate policies, should be incorporated in decision making to maximize the overall benefits. The results help to develop an optimized technological roadmap which simultaneously meets the GHG reduction target, alleviates air pollution, and protects public health in California.

An important reason why the health cobenefits are highly sensitive to decarbonization technologies in California is that natural gas serves as the predominant energy source for stationary sources at present. ${ }^{12}$ This is in sharp contrast to many countries or regions (e.g., China, the northeastern states of the United States) where coal, a dirtier fuel, is still a major energy source so that most feasible decarbonization technologies can lead to considerable air 
quality and health cobenefits. Therefore, the finding of high sensitivity to selected decarbonization pathway may not apply to all countries/regions in the world given the diverse energy structures, but it holds strong potential for generalization in countries/regions with a similar clean energy structure, extending this work's global reach and impact.

\section{Supplementary Material}

Refer to Web version on PubMed Central for supplementary material.

\section{ACKNOWLEDGMENTS}

This work was supported by the UCLA Sustainable LA Grand Challenge Project, NSF Grant AGS-1701526 and NASA ROSES TASNNP Grant 80NSSC18K0985. We would like to acknowledge high-performance computing support from Cheyenne (doi:10.5065/D6RX99HX) provided by NCAR's Computational and Information Systems Laboratory, sponsored by the National Science Foundation. The views, opinions, findings, and conclusions or recommendations expressed in this paper are strictly those of the authors. They do not necessarily reflect the views of funding agencies and/or authors' affiliated institutes.

\section{REFERENCES}

(1). California Gov. Arnold Schwarzenegger, Executive Order S-3-05. http://static1.squarespace.com/ static/549885d4e4b0ba0bff5dc695/t/54d7f1e0e4b0f0798cee3010/1423438304744/California + Executive+Order+S-3-05+(June+2005).pdf (12 1, 2018).

(2). Zapata C; Muller N; Kleeman MJ PM2.5 co-benefits of climate change legislation part 1: California's AB 32. Clim. Change 2013, 117 (1-2), 377-397.

(3). Thompson TM; Rausch S; Saari RK; Selin NE A systems approach to evaluating the air quality co-benefits of US carbon policies. Nat. Clim. Change 2014, 4 (10), 917-923.

(4). Markandya A; Sampedro J; Smith SJ; Van Dingenen R; Pizarro-Irizar C; Arto I; Gonzalez-Eguino $M$ Health co-benefits from air pollution and mitigation costs of the Paris Agreement: a modelling study. Lancet Planet Health 2018, 2 (3), e126-e133. [PubMed: 29615227]

(5). American Lung Association State of the Air 2018; American Lung Association: Chicago, IL, 2018.

(6). Zapata CB; Yang C; Yeh S; Ogden J; Kleeman MJ Low-carbon energy generates public health savings in California. Atmos. Chem. Phys 2018, 18 (7), 4817-4830.

(7). Thompson TM; Rausch S; Saari RK; Selin NE Air quality co-benefits of subnational carbon policies. J. Air Waste Manage. Assoc 2016, 66 (10), 988-1002.

(8). Kleeman MJ; Zapata C; Stilley J; Hixson M PM2.5 co-benefits of climate change legislation part 2: California governor's executive order S-3-05 applied to the transportation sector. Clim. Change 2013, 117 (1-2), 399-414.

(9). Jacobson MZ; Delucchi MA; Cameron MA; Frew BA Low-cost solution to the grid reliability problem with $100 \%$ penetration of intermittent wind, water, and solar for all purposes. Proc. Natl. Acad. Sci. U. S. A 2015, 112 (49), 15060-15065. [PubMed: 26598655]

(10). Shindell D; Kuylenstierna JCI; Vignati E; van Dingenen R; Amann M; Klimont Z; Anenberg SC; Muller N; Janssens-Maenhout G; Raes F; Schwartz J; Faluvegi G; Pozzoli L; Kupiainen K; Hoglund-Isaksson L; Emberson L; Streets D; Ramanathan V; Hicks K; Oanh NTK; Milly G; Williams M; Demkine V; Fowler D Simultaneously Mitigating Near-Term Climate Change and Improving Human Health and Food Security. Science 2012, 335 (6065), 183-189. [PubMed: 22246768]

(11). Ou Y; Shi WJ; Smith SJ; Ledna CM; West JJ; Nolte CG; Loughlin DH Estimating environmental co-benefits of US low-carbon pathways using an integrated assessment model with state-level resolution. Appl. Energy 2018, 216, 482-493. [PubMed: 29713111]

(12). U.S. Energy Information Administration, California Energy Consumption Estimates. https:// www.eia.gov/state/?sid=CA $(7$ 1, 2018). 
(13). Driscoll CT; Buonocore JJ; Levy JI; Lambert KF; Burtraw D; Reid SB; Fakhraei H; Schwartz J US power plant carbon standards and clean air and health co-benefits. Nat. Clim. Change 2015, 5 (6), 535-540.

(14). Anderson CM; Kissel KA; Field CB; Mach KJ Climate Change Mitigation, Air Pollution, and Environmental Justice in California. Environ. Sci. Technol 2018, 52 (18), 10829-10838. [PubMed: 30179479]

(15). U.S. Environmental Protection Agency AP-42: Compilation of Air Emissions Factors; U.S. Environmental Protection Agency,: 2018.

(16). California Air Resources Board. California Greenhouse Gas Emission Inventory Program. https:// www.arb.ca.gov/cc/inventory/inventory.htm $(10$ 1, 2018).

(17). U.S. Energy Information Administration, Emissions of greenhouse gases in the U.S https:// www.eia.gov/environment/emissions/ghg_report/ghg_carbon.php $(7$ 1, 2018).

(18). Argonne National Laboratory The Greenhouse Gases, Regulated Emissions, and Energy use in Transportation Model; Argonne National Laboratory: Lemont, IL, USA, 2016.

(19). California Air Resources Board An Inventory of Ecosystem Carbon in California's Natural \& Working Lands; California Air Resources Board: Sacramento, CA, 2018.

(20). California Senate. SB-100 California Renewables Portfolio Standard Program: emissions of greenhouse gases. https://leginfo.legislature.ca.gov/faces/billNavClient.xhtml? bill_id=201720180SB100 (4 4, 2019).

(21). California Air Resources Board. Progress Report - California's Sustainable Communities and Climate Protection Act; California Air Resources Board: Sacramento, CA, 2018.

(22). California Senate, SB-375 Transportation planning: travel demand models: sustainable communities strategy: environmental review. https://leginfo.legislature.ca.gov/faces/ billNavClient.xhtml?bill_id=200720080SB375 (4 2, 2019).

(23). California Energy Comission. 2016 Building Energy Efficiency Standards for Residential and NonResidential Buildings. https://www.energy.ca.gov/2015publications/CEC-400-2015-037/ CEC-400-2015-037-CMF.pdf (4 2, 2019).

(24). Williams JH; DeBenedictis A; Ghanadan R; Mahone A; Moore J; Morrow WR; Price S; Torn MS The Technology Path to Deep Greenhouse Gas Emissions Cuts by 2050: The Pivotal Role of Electricity. Science 2012, 335 (6064), 53-59. [PubMed: 22116030]

(25). California Air Resources Board. CEPAM: Emission Projections By Summary Category. https:// www.arb.ca.gov/app/emsinv/fcemssumcat/fcemssumcat2016.php $(10$ 1, 2018).

(26). US Environmental Protection Agency. New Source Performance Standards. https://www.epa.gov/ stationary-sources-air-pollution/new-source-performance-standards $(3$ 1, 2019).

(27). NOAA, NOAA ESRL CSD Projects: CalNex 2010. https://www.esrl.noaa.gov/csd/projects/ calnex/ (12 1, 2018).

(28). Wang K; Zhang Y; Yahya K; Wu SY; Grell G Implementation and initial application of new chemistry-aerosol options in WRF/Chem for simulating secondary organic aerosols and aerosol indirect effects for regional air quality. Atmos. Environ 2015, 115, 716-732.

(29). Zhao B; Wang SX; Wang JD; Fu JS; Liu TH; Xu JY; Fu X; Hao JM Impact of national NOx and SO2 control policies on particulate matter pollution in China. Atmos. Environ 2013, 77, 453463.

(30). Zhao B; Wu WJ; Wang SX; Xing J; Chang X; Liou KN; Jiang JH; Gu Y; Jang C; Fu JS; Zhu Y; Wang JD; Lin Y; Hao JM A modeling study of the nonlinear response of fine particles to air pollutant emissions in the Beijing-Tianjin-Hebei region. Atmos. Chem. Phys 2017, 17, 1203112050.

(31). Yarwood G; Rao S; Yocke M; Whitten GZ Final Reportupdates to the Carbon Bond Chemical Mechanism: CB05 (Report RT-04-00675); Yocke and Co.: Novato, CA, 2005; p 246.

(32). Sarwar G; Luecken D; Yarwood G; Whitten GZ; Carter WPL Impact of an updated carbon bond mechanism on predictions from the CMAQ modeling system: Preliminary assessment. J. Appl. Meteorol Clim 2008, 47 (1), 3-14.

(33). Ahmadov R; McKeen SA; Robinson AL; Bahreini R; Middlebrook AM; de Gouw JA; Meagher J; Hsie EY; Edgerton E; Shaw S; Trainer M A volatility basis set model for summertime 
secondary organic aerosols over the eastern United States in 2006. J. Geophys Res-Atmos 2012, 117, D06301.

(34). US Environmental Protection Agency. National Emissions Inventory (NEI). https://www.epa.gov/ air-emissions-inventories/national-emissions-inventory-nei $(12$ 10, 2018).

(35). US Environmental Protection Agency, Air Pollutant Emissions Trends Data. https:// www.epa.gov/air-emissions-inventories/air-pollutant-emissions-trends-data (12 10 2016).

(36). U.S. Environmental Protection Agency. Regulatory Impact Analysis of the Final Revisions to the National Ambient Air Quality Standards for Ground-Level Ozone. http://www.epa.gov/ scram001/reports/EPA-454-R-07-003.pdf (12 6, 2018).

(37). U.S. Environmental Protection Agency. Regulatory Impact Analysis for the Final Revisions to the National Ambient Air Quality Standards for Particulate Matter. https://www3.epa.gov/ttnecas1/ regdata/RIAs/finalria.pdf $(126,2018)$.

(38). US Environmental Protection Agency. Environmental Benefits Mapping and Analysis Program Community Edition User's Manual and Appendices. https://www.epa.gov/sites/production/files/ 2015-04/documents/benmap-ce_user_manual_march_2015.pdf $(12$ 6, 2018).

(39). Turner MC; Jerrett M; Pope CA; Krewski D; Gapstur SM; Diver WR; Beckerman BS; Marshall JD; Su J; Crouse DL; Burnett RT Long-Term Ozone Exposure and Mortality in a Large Prospective Study. Am. J. Respir. Crit. Care Med 2016, 193 (10), 1134-1142. [PubMed: 26680605]

(40). Krewski D; Jerrett M; Burnett RT; Ma R; Hughes E; Shi Y; Turner MC; Pope CA III; Thurston G; Calle EE; Thun MJ Extended Follow-Up and Spatial Analysis of the American Cancer Society Study Linking Particulate Air Pollution and Mortality; Health Effects Institute: Boston, MA, 2009; p 142.

(41). Jerrett M; Burnett RT; Pope CA; Ito K; Thurston G; Krewski D; Shi YL; Calle E; Thun M LongTerm Ozone Exposure and Mortality. N. Engl. J. Med 2009, 360 (11), 1085-1095. [PubMed: 19279340]

(42). Barrett SRH; Speth RL; Eastham SD; Dedoussi IC; Ashok A; Malina R; Keith DW Impact of the Volkswagen emissions control defeat device on US public health. Environ. Res. Lett 2015, 10 (11) DOI: 10.1088/1748-9326/10/11/114005.

(43). US Environmental Protection Agency. Guidelines For Preparing Economic Analysis; US Environmental Protection Agency: Research Triangle Park, NC, 2010.

(44). California Air Resources Board. DRAFT Review of Studies that Estimated the Costs of $\mathrm{CO}_{2}$ Emission Reductions. https:/www.arb.ca.gov/cc/scopingplan/economics-sp/meetings/060308/ ce_appendix_a.pdf $(4$ 2, 2019).

(45). Gillingham K; Stock JH The Cost of Reducing Greenhouse Gas Emissions. Journal Of Economic Perspectives 2018, 32 (4), 53-72.

(46). de Pee A; Pinner D; Roelofsen O; Somers K; Speelman E Decarbonization of industrial sectors: The next frontier; McKinsey \& Company: Amsterdam, Netherlands, 2018.

(47). U.S. Department of Energy Wind Vision: A New Era for Wind Power in the United States; U.S. Department of Energy: Oak Ridge, TN, 2015.

(48). California Air Resources Board. California Cap-and-Trade Program Summary of CaliforniaQuebec Joint Auction Settlement Prices and Results. https://www.arb.ca.gov/cc/capandtrade/ auction/results_summary.pdf $(4$ 2, 2019).

(49). Huang M; Bowman KW; Carmichael GR; Lee M; Chai TF; Spak SN; Henze DK; Darmenov AS; da Silva AM Improved western US background ozone estimates via constraining nonlocal and local source contributions using Aura TES and OMI observations. J. Geophys Res-Atmos 2015, 120 (8), 3572-3592.

(50). Oltmans SJ; Lefohn AS; Harris JM; Shadwick DS Background ozone levels of air entering the west coast of the US and assessment of longer-term changes. Atmos. Environ 2008, 42 (24), 6020-6038.

(51). Fiore AM; Oberman JT; Lin MY; Zhang L; Clifton OE; Jacob DJ; Naik V; Horowitz LW; Pinto JP; Milly GP Estimating North American background ozone in U.S. surface air with two independent global models: Variability, uncertainties, and recommendations. Atmos. Environ 2014, 96, 284-300. 
(52). Emery C; Jung J; Downey N; Johnson J; Jimenez M; Yarwood G; Morris R Regional and global modeling estimates of policy relevant background ozone over the United States. Atmos. Environ 2012, 47, 206-217.

(53). Zhang L; Jacob DJ; Downey NV; Wood DA; Blewitt D; Carouge CC; van Donkelaar A; Jones DBA; Murray LT; Wang YX Improved estimate of the policy-relevant background ozone in the United States using the GEOS-Chem global model with 1/2 degrees $\times 2 / 3$ degrees horizontal resolution over North America. Atmos. Environ 2011, 45 (37), 6769-6776.

(54). Jin L; Loisy A; Brown NJ Role of meteorological processes in ozone responses to emission controls in California's San Joaquin Valley. J. Geophys Res-Atmos 2013, 118 (14), 8010-8022.

(55). Downey N; Emery C; Jung J; Sakulyanontvittaya T; Hebert L; Blewitt D; Yarwood G Emission reductions and urban ozone responses under more stringent US standards. Atmos. Environ 2015, 101, 209-216.

(56). Xing J; Wang SX; Jang C; Zhu Y; Hao JM Nonlinear response of ozone to precursor emission changes in China: a modeling study using response surface methodology. Atmos. Chem. Phys 2011, 11 (10), 5027-5044.

(57). California Senate, SB-535 California Global Warming Solutions Act of 2006: Greenhouse Gas Reduction Fund. https://leginfo.legislature.ca.gov/faces/billNavClient.xhtml? bill_id=201120120SB535 (4 2, 2019). 


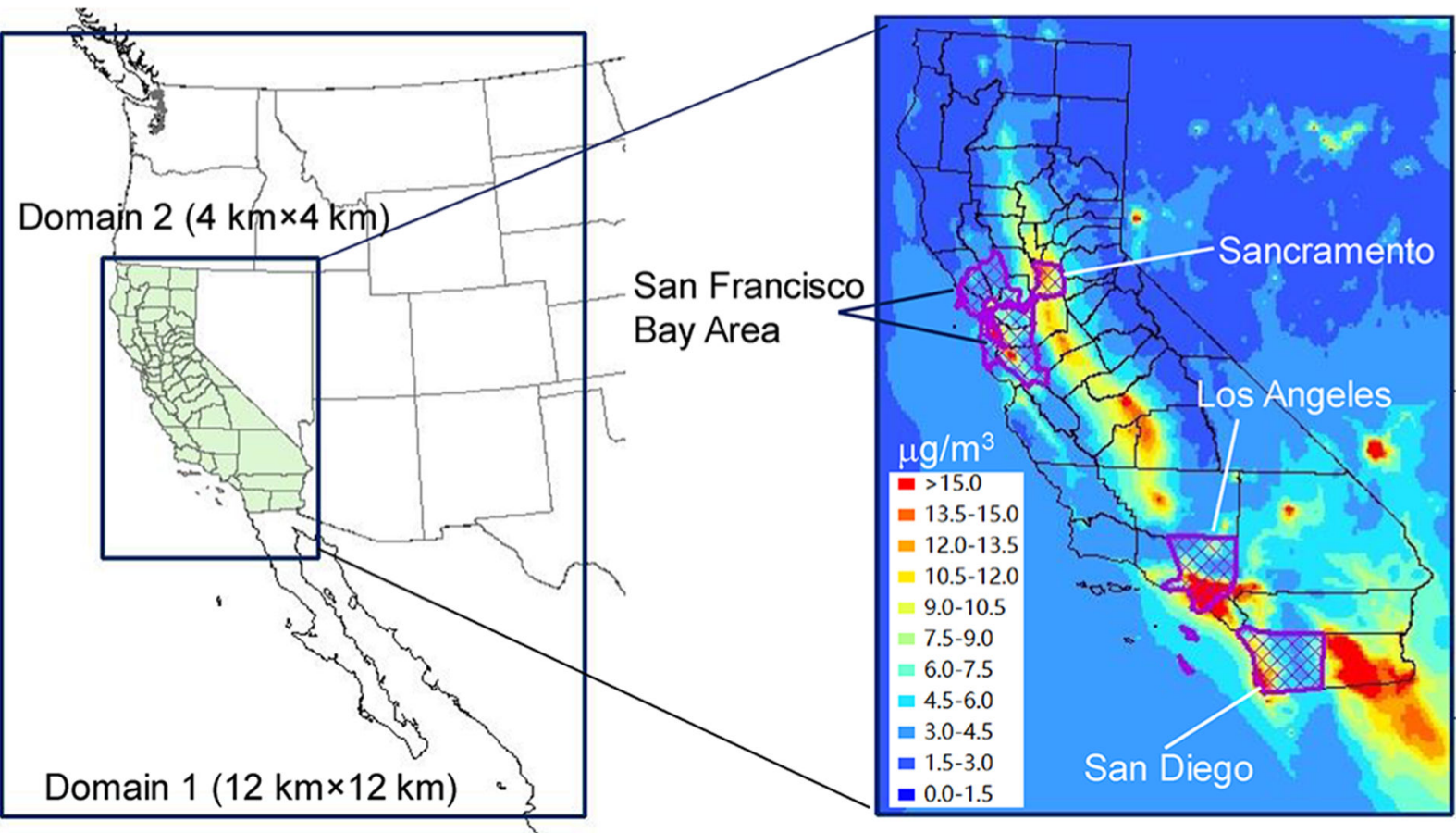

Figure 1.

Illustration of modeling domains used in this study (left) and four largest metropolitan regions in California (right, purple polygons). The colored background on the right represents simulated annual mean $\mathrm{PM}_{2.5}$ concentrations in the business-as-usual (BAU) scenario in 2050. 

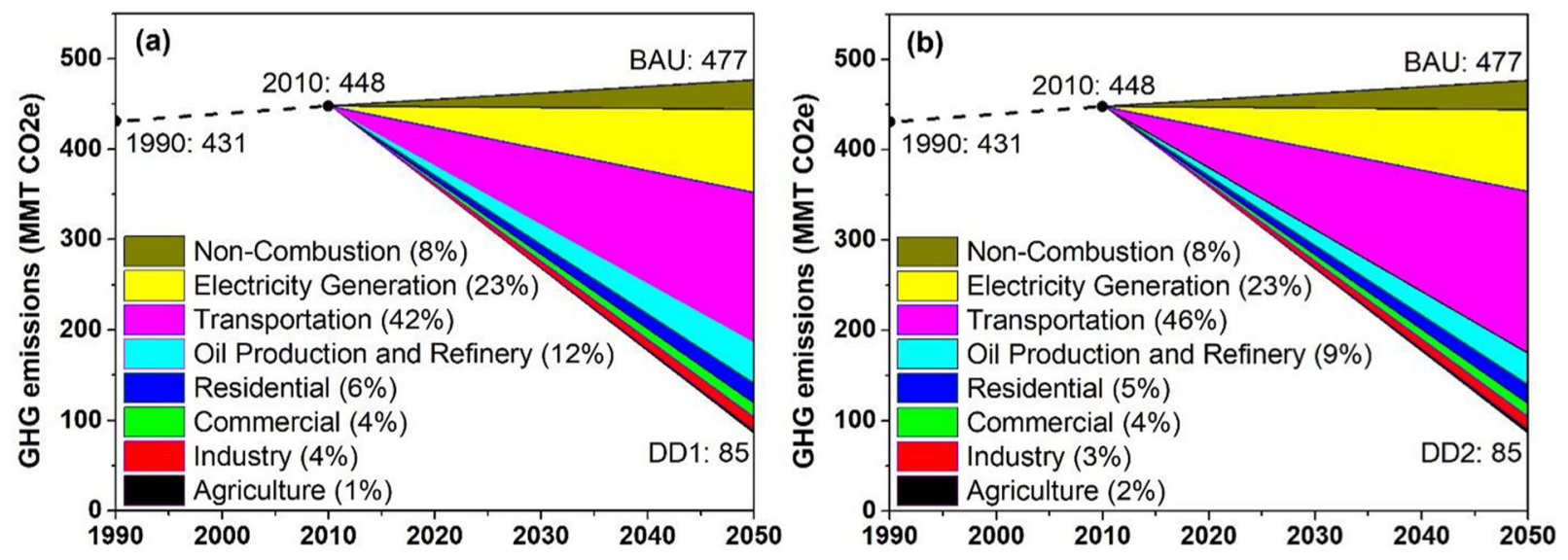

Figure 2.

California statewide greenhouse gas (GHG) emissions in (a) DD1 and (b) DD2 scenarios, and the contribution of each sector to GHG emission reduction from the BAU levels. The numbers in the legends represent the percentage contribution of each sector to emission reductions from BAU to DD1/DD2 in 2050. 


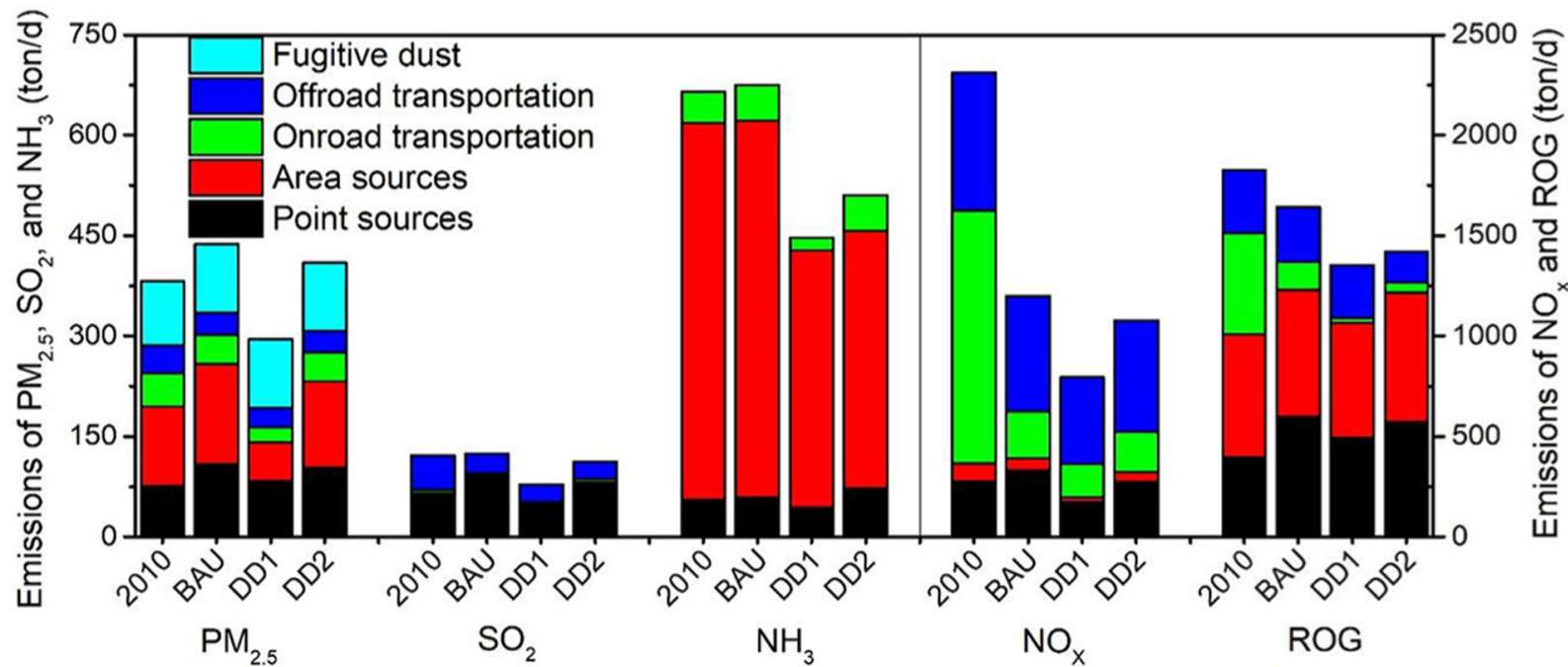

Figure 3.

California statewide emissions of major air pollutants in 2010 and under different scenarios in 2050. Point sources include electricity generation, oil production and refinery, and largescale industry. Fugitive dust includes paved road dust, unpaved road dust, and wind-blown dust. Area sources include agriculture, commercial, residential, small-scale industry, and noncombustion sources except for fugitive dust. 
Reduction from BAU to DD1

Reduction from BAU to DD2
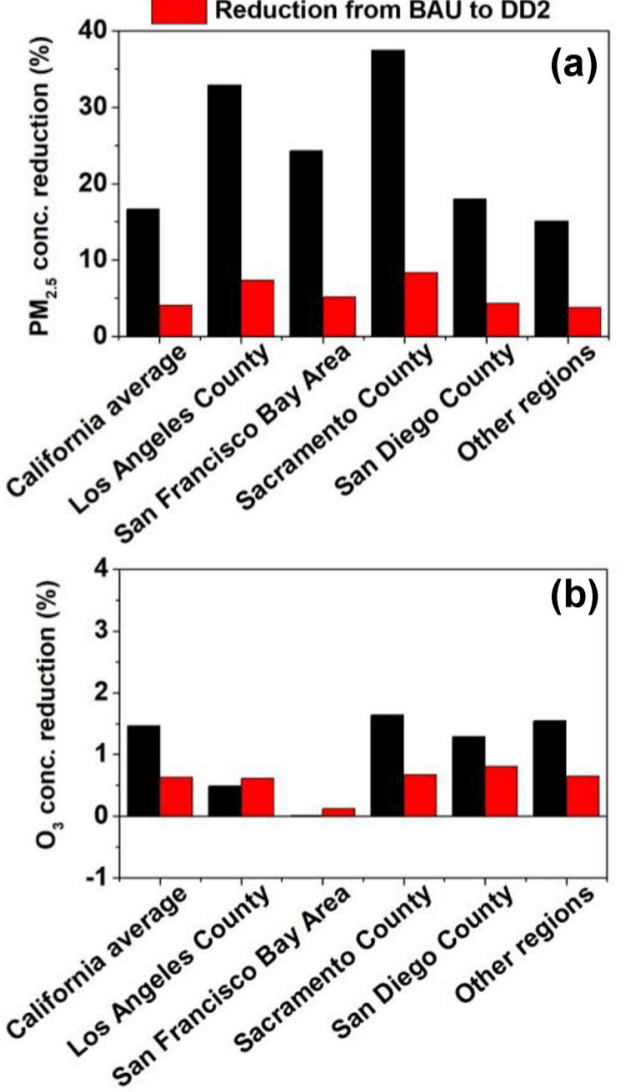
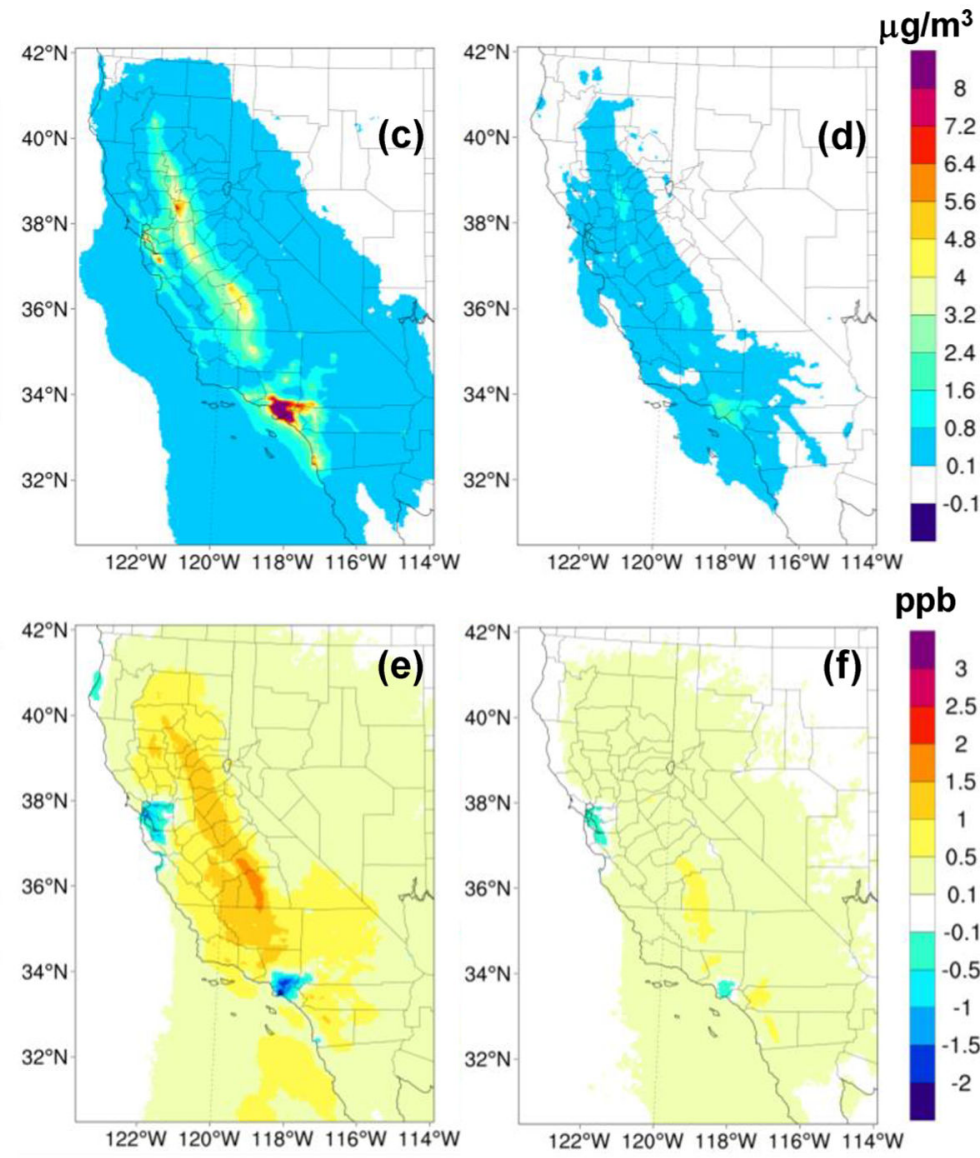

ppb

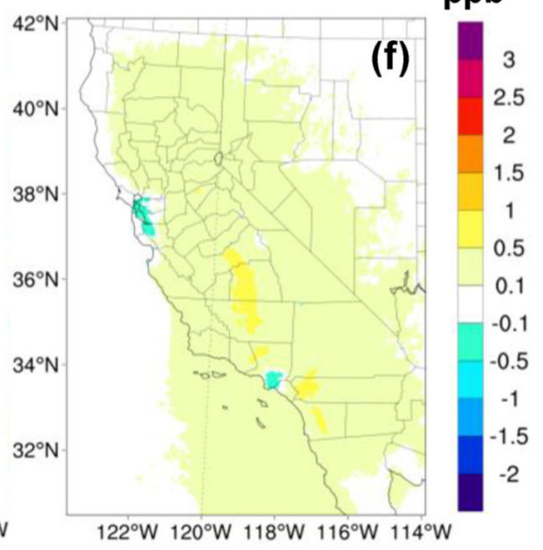

Figure 4.

Reductions in annual mean $\mathrm{PM}_{2.5}$ and $\mathrm{O}_{3}$ concentrations due to the enforcement of deep decarbonization policies: (a,b) fractional reduction in concentrations of (a) $\mathrm{PM}_{2.5}$ and (b) $\mathrm{O}_{3}$ from the BAU to DD1/DD2 scenarios; (c,d) spatial distribution of the reductions in $\mathrm{PM}_{2.5}$ concentrations (c) from the BAU to DD1 scenario and (d) from the BAU to DD2 scenario; $(\mathrm{e}, \mathrm{f})$ the same as $(\mathrm{c}, \mathrm{d})$ but for $\mathrm{O}_{3}$ concentrations. $\mathrm{All}_{3}$ concentrations are measured in maximum daily 8-h average (MDA8). The four largest Californian metropolitan regions in (a) and (b) include both urban centers and surrounding suburban areas within the administrative boundaries, as illustrated in Figure 1. 

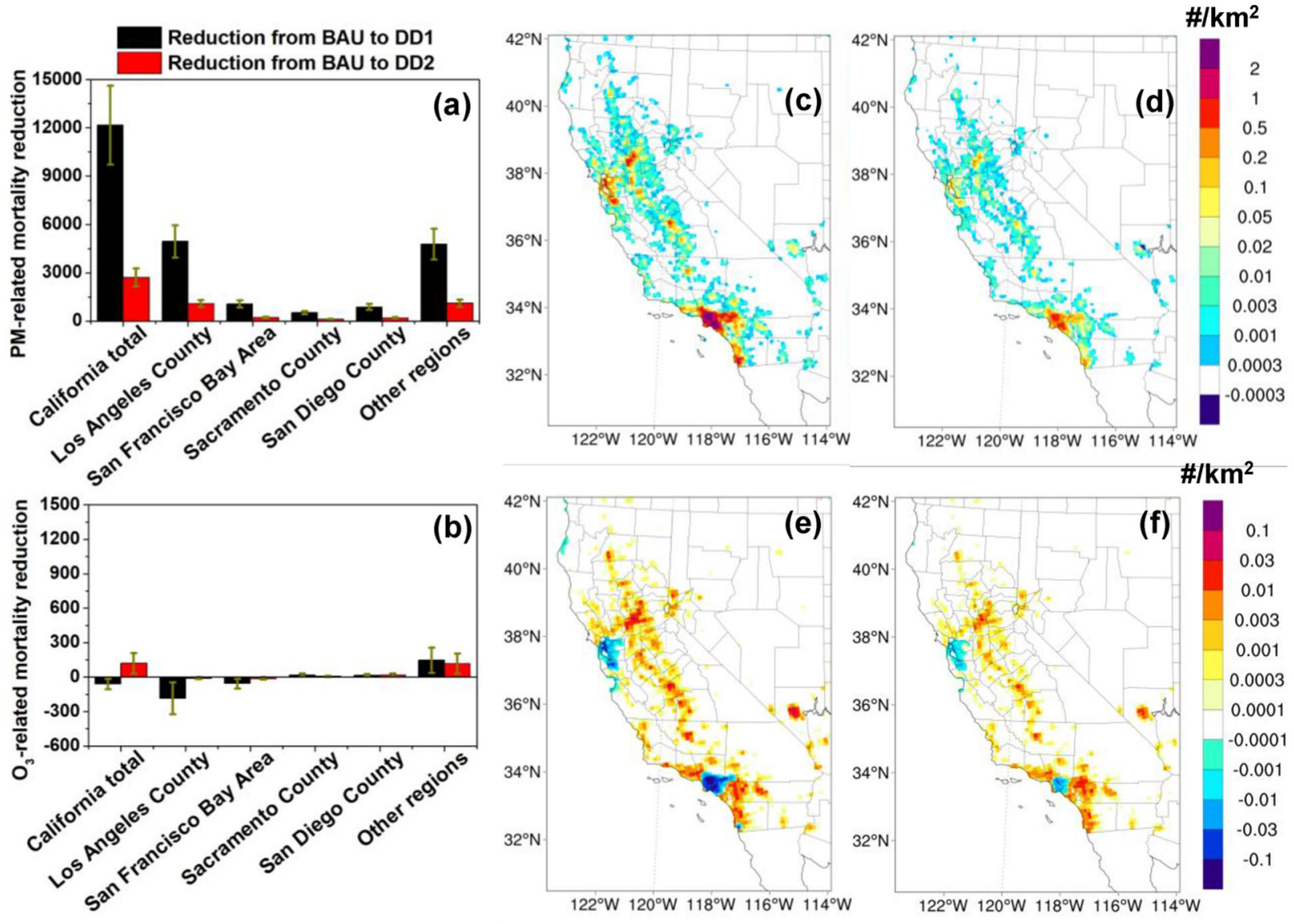

Figure 5.

Reductions in $\mathrm{PM}_{2.5}$ and $\mathrm{O}_{3}$-related mortality in 2050 due to the enforcement of deep decarbonization policies: (a,b) reduction in (a) $\mathrm{PM}_{2.5}$-related and (b) $\mathrm{O}_{3}$-related premature mortality from the BAU to DD1/DD2 scenarios; (c,d) spatial distribution of the reductions in $\mathrm{PM}_{2.5}$-related premature mortality (c) from the BAU to DD1 scenario and (d) from the BAU to DD2 scenario; $(\mathrm{e}, \mathrm{f})$ the same as $(\mathrm{c}, \mathrm{d})$ but for $\mathrm{O}_{3}$-related mortality. The error bars in $(\mathrm{a}, \mathrm{b})$ represent the $95 \%$ confidence intervals (CI) calculated using Monte Carlo analysis based on the uncertainty in the parameters of concentration-response functions (CRFs). 


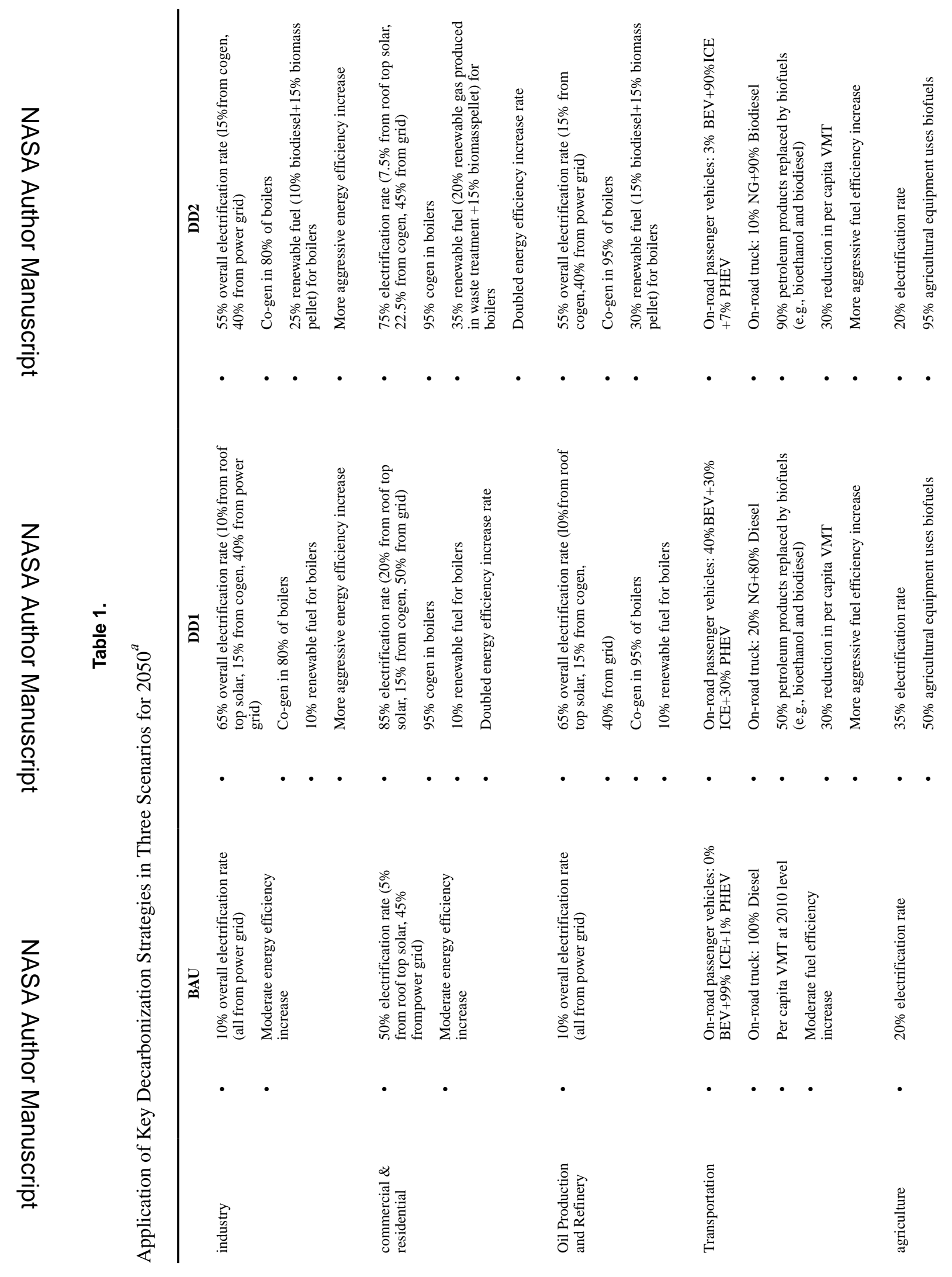




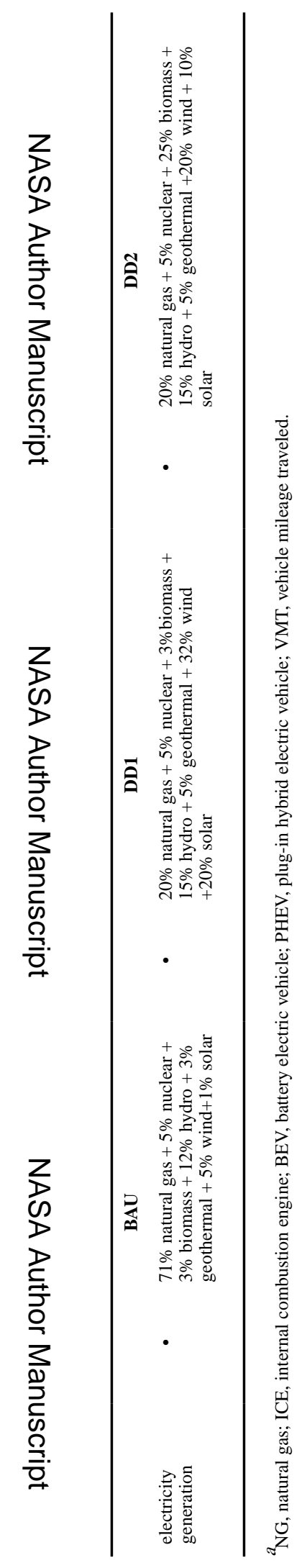

